\title{
Riqueza e frequência de espécies de fungos micorrízicos arbusculares em genótipos de amendoim forrageiro no Acre, Norte do Brasil
}

\author{
José Marlo Araújo de AZEVEDO ${ }^{1 *}$, Giselle Mariano Lessa de ASSIS $^{2}$, Orivaldo José SAGGIN JUNIOR ${ }^{3}$, \\ Hellen Sandra Freires da Silva AZEVEDO ${ }^{4}$ \\ 1 Instituto Federal do Acre (IFAC), Programa de Pós-graduação em Biotecnologia e Recursos genéticos. Av. Mâncio Lima, № 83, CEP: 69915-900, Fone: (68) 3322-1165. \\ Cruzeiro do Sul, Acre, Brasil. \\ 2 Embrapa Acre. Rodovia BR-364, km 14, CEP: 69900-056, Fone: (68) 3212-3230, Fax: (68) 3212-3284. Rio Branco, Acre, Brasil. giselle.assis@embrapa.br \\ ${ }^{3}$ Embrapa Agrobiologia. Rodovia BR-465, km 7, CEP: 23891-000, Fone: (21) 3441-1565, Fax: (21) 2682-1230. Seropédica, RJ, Brasil. orivaldo.saggin@embrapa.br \\ ${ }^{4}$ Universidade Federal do Acre, Pós-graduação em Ciência, Inovação e Tecnologia para a Amazônia. BR 364, km 04, Distrito industrial, CEP: 69915-900, Fone: (68) 3212-3200. \\ Rio Branco, Acre, Brasil. hellenfreires@gmail.com \\ * Autor Correspondente: jose.azevedo@ifac.edu.br
}

\section{RESUMO}

O potencial da cultura do amendoim forrageiro associada aos fungos micorrízicos arbusculares (FMA) tem sido objeto de alguns estudos, porém a influência do genótipo sobre essa associação é pouco relatada. O objetivo deste trabalho foi determinar a densidade de esporos, riqueza de espécies, a frequência e ocorrência relativa de FMAs associados a genótipos de amendoim forrageiro. Foram coletadas amostras simples de solo de 45 genótipos pertencentes ao Banco Ativo de Germoplasma na Embrapa Acre. As amostras de solo foram coletadas a $5 \mathrm{~cm}$ de profundidade, com três repetiçóes em delineamento inteiramente casualizado. As amostras de solo foram levadas para o Laboratório de Micorrizas da Embrapa Agrobiologia, para determinaçáo da densidade de esporos e identificação das espécies de FMAs. Foi realizada análise de variância e teste de Scott-Knott. Destacaram-se quatro genótipos de $A$. pintoi e dois híbridos interespecíficos, que apresentaram maior densidade de esporos. Foi verificada a ocorrência de 21 espécies de FMAs nas amostras de solo. A riqueza variou entre três e dez espécies. Três espécies de FMAs apresentaram elevada frequência relativa: Glomus macrocarpum (100,0\%), Acaulospora tuberculata (97,8\%) e Racocetra verrucosa (88,99\%). Conclui-se, assim que: (i) Existe variabilidade genética entre os genótipos de amendoim forrageiro quanto à promoção da esporulação e riqueza de espécies de FMAs nas suas rizosferas; (ii) As espécies de FMAs Glomus macrocarpum, Acaulospora tuberculata, Racocetra verrucosa possuem alta presença na rizosfera dos genótipos de amendoim forrageiro, devendo serem estudadas visando sua introdução na cultura.

PALAVRAS-CHAVE: Arachis pintoi, Arachis repens, micorrizas, levantamento taxonômico, Glomeromycota

\section{Richness and frequency of species of arbuscular mycorrhizal fungi in forage peanut genotypes in Acre, northern Brazil}

\begin{abstract}
The potential of the forage peanut crop associated with arbuscular mycorrhizal fungi (AMF) has been the subject of some studies, but the influence of the genotype on this association is poorly understood. The objective of this study was to determine the spore density, species richness, relative frequency and occurrence of AMF associated with forage peanut genotypes. Simple soil samples were collected from 45 genotypes of Active Germplasm Bank at Embrapa Acre. Soil samples were collected at 5 $\mathrm{cm}$ depth, with three replicates in a completely randomized design. Soil samples were taken to the Mycorrhizae Laboratory of Embrapa Agrobiologia for determination of spore density and identification of AMF species. Analysis of variance and ScottKnott test were performed. Four genotypes of $A$. pinto $i$ and two interspecific hybrids, which showed higher spore density, stood out. It was found the occurrence of 21 AMF species in the soil samples. The richness ranged between three and ten species. Three AMF species showed high relative frequency: Glomus macrocarpum (100.0\%), Acaulospora tuberculata (97.8\%) and Racocetra verrucosa (88.9\%). It was concluded that: (i) Regarding inducement of AMF sporulation and species richness, there is genetic variability among forage peanut genotypes, (ii) Glomus macrocarpum, Acaulospora tuberculata, Racocetra verrucosa are often present in the rhizosphere of forage peanut genotypes and should be studied aiming its introduction in the culture.
\end{abstract}

KEYWORDS: Arachis pintoi, Arachis repens, mycorrhizae, taxonomic survey, Glomeromycota 


\section{INTRODUÇÃO}

Dentre as leguminosas forrageiras tropicais, as espécies Arachis pintoi Krapovickas \& Gregory, Arachis repens Handro e Arachis glabrata Benth., conhecidas como 'amendoim forrageiro', se destacam apresentando elevada persistência em consórcio e boas características bromatológicas (Andrade et al. 2006). Estudos demonstram que o amendoim forrageiro é pouco seletivo, nodulando com grande variedade de rizóbios e formando micorrizas com diversas espécies de fungos micorrízicos arbusculares (FMAs), beneficiando o sistema pastoril (Soares et al. 2006; Gómez-Carabalí et al. 2011).

FMAs autóctones são encontrados colonizando o amendoim forrageiro, sendo os gêneros mais comuns Glomus, Acaulospora e Scutellospora (Santos et al. 2001; Miranda et al. 2010). Quanto mais complexo for um agroecossistema, maior é a diversidade de espécies de FMAs (Burrows e Pfleger 2002). Entretanto, o amendoim forrageiro em monocultivo apresentou diversidade de fungos comparáveis a ecossistemas complexos, indicando aumentar a quantidade de FMAs e, assim, melhorar a qualidade biológica do solo (Miranda et al. 2010).

Segundo Janos (1988), o grau de interaçáo entre FMAs e planta depende mais do genótipo da planta, onde a nutriçấo do vegetal é considerada o principal fator controlador da associação. Este autor sugere que a dependência micorrízica que uma planta apresenta é uma característica intrínseca, de herança genética. Assim, a variabilidade genética existente entre acessos de uma mesma espécie vegetal ou entre diferentes espécies pode influenciar o grau de resposta à associação micorrízica e determinar amplitude das espécies de FMAs capazes de estabelecer micorrizas eficientes (Janos 2007). Raízes de aveias analisadas em diferentes profundidades no solo, em diferentes altitudes geográficas e em diferentes cultivarem sob a mesma altitude indicam que a altitude não afeta a colonização radicular, mas o genótipo das plantas influencia significativamente este indicador de micorrização (Yang et al. 2010). Os autores também verificaram que a altitude e o genótipo das plantas afetam as proporçốes de colonização entre arbúsculos e vesículas, o que pode indicar que esses fatores influenciam diferentes espécies de fungos a colonizar as raízes. Portanto, estudos de micorrizas devem ser mais explícitos sobre a origem da planta e do FMA, pois segundo Van der Heijden e Kuyper (2001) o efeito da origem da planta e do fungo são importantes no funcionamento simbiótico.

A identificação de genótipos de amendoim forrageiro capazes de estabelecer associaçôes funcionais com FMAs é importante para selecionar cultivares mais produtivas, de alta qualidade nutricional e que apresentem baixa exigência de fósforo. Assim, é primordial o conhecimento da interação entre genótipos de amendoim forrageiro e espécies de
FMAs. O objetivo deste estudo foi determinar a densidade de esporos, a riqueza de espécies, a frequência e a ocorrência relativa de fungos micorrízicos arbusculares associados a genótipos de amendoim forrageiro mantidos no Banco Ativo de Germoplasma da Embrapa Acre.

\section{MATERIAL E MÉTODOS}

O estudo foi realizado no Banco Ativo de Germoplasma de Amendoim Forrageiro localizado na Embrapa Acre, município de Rio Branco, a 1001'25”'S e 6741'21" W. O solo da área foi caracterizado como Latossolo Vermelho. A precipitação anual da regiâo varia entre 1.800 e $2.000 \mathrm{~mm}$, com temperatura média anual de $25^{\circ} \mathrm{C}$. As estaçôes, seca e úmida, são bem definidas: o período chuvoso compreende os meses de outubro a maio e o seco de junho a setembro (Programa Estadual de Zoneamento Ecológico-Econômico do Acre 2006).

O Banco Ativo de Germoplasma de Amendoim Forrageiro foi estabelecido nesta área em 2006. Na época da implantação, a área foi adubada com $50 \mathrm{~kg} \mathrm{ha}^{-1}$ de $\mathrm{P}_{2} \mathrm{O}_{5}$ (superfosfato triplo), $40 \mathrm{~kg} \mathrm{ha}^{-1}$ de $\mathrm{K}_{2} \mathrm{O}$ (cloreto de potássio) e $40 \mathrm{~kg} \mathrm{ha}^{-1}$ de FTE BR $12^{\circ}$ (Nutriplant Tecnologia e Nutrição, Barueri, São Paulo, Brasil) que contém os seguintes nutrientes: cálcio $71 \mathrm{~g} \mathrm{~kg}^{-1}$; enxofre $57 \mathrm{~g} \mathrm{~kg}^{-1}$; zinco $90 \mathrm{~g} \mathrm{~kg}^{-1}$; boro $18 \mathrm{~g} \mathrm{~kg}^{-1}$; cobre $8 \mathrm{~g}$ $\mathrm{kg}^{-1}$; manganês $20 \mathrm{~g} \mathrm{~kg}^{-1}$; molibdênio $1 \mathrm{~g} \mathrm{~kg}^{-1}$. Não foi realizada aplicação de nitrogênio na área nem a inoculação com rizóbios na época do plantio, considerando que essas espécies são pouco seletivas quanto a bactérias fixadoras de nitrogênio. $\mathrm{Na}$ época da colheita das amostras observou-se ocorrência de nódulos em todos os genótipos avaliados. Em agosto de 2008, foram coletadas três amostras compostas de solo formadas a partir de 20 amostras simples, cada uma, provenientes da área do Banco Ativo de Germoplasma. Em virtude das características físicas e químicas da área experimental ser bastante semelhantes, apenas é apresentado o resultado da análise de uma das amostras compostas. As características químicas e texturais do solo de uma amostra composta sáo detalhadas na Tabela 1 .

O Banco Ativo de Germoplasma estudado é composto por cerca de 110 genótipos, os quais são representados principalmente por acessos das espécies $A$. pintoi, A. repens e híbridos intra e interespecíficos. Os genótipos foram estabelecidos em parcelas de $4 \mathrm{~m}^{2}$, por meio de mudas em 2006. Em agosto de 2008, período caracterizado como época seca, foi coletado amostras simples de solo das parcelas de 45 genótipos do Banco Ativo de Germoplasma (Tabela 2), para determinaçấo da densidade de esporos e identificação das espécies de FMAs, viabilizando o cálculo da riqueza e da frequência relativa de espécies.

As amostras simples de solo foram obtidas na zona da rizosfera a $5 \mathrm{~cm}$ de profundidade, sendo realizadas três repetições. Três amostras simples de solo (A1, A2 e A3) também com três repetiçóes foram coletadas a $5 \mathrm{~cm}$ 
Tabela 1- Características químicas e texturais de uma amostra composta do Latossolo Vermelho coletada na profundidade de 0-20 $\mathrm{cm}$ em diferentes áreas dentro do Banco Ativo de Germoplasma de Amendoim Forrageiro da Embrapa Acre

\begin{tabular}{|c|c|c|c|c|c|c|c|c|c|c|c|c|c|}
\hline \multirow{2}{*}{$\begin{array}{l}\text { pH e m } \\
\mathrm{H}_{2} \mathrm{O}(2: 1)\end{array}$} & $\mathrm{Al}^{+3}$ & $\mathrm{Ca}^{+2}$ & $\mathrm{Mg}^{+2}$ & $\mathrm{~K}$ & CTC & $\mathrm{H}+\mathrm{Al}$ & $\mathrm{P}$ & M.0 & V & $C$ & Argila & Silte & Areia \\
\hline & \multicolumn{6}{|c|}{ 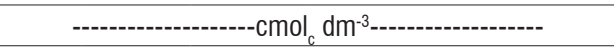 } & $\mathrm{mg} \mathrm{dm}^{-3}$ & \multicolumn{2}{|c|}{-------\%----- } & $\mathrm{g} \mathrm{kg}^{-1}$ & \multicolumn{3}{|c|}{------\%----- } \\
\hline 5,2 & 0,7 & 3,0 & 0,7 & 0,2 & 6,92 & 3,02 & 3,0 & 15,0 & 56,36 & 0,87 & 31,81 & 6,35 & 61,84 \\
\hline
\end{tabular}

pH - potencial hidrogeniônico; $\mathrm{Al}^{+3}$ - alumínio; $\mathrm{Ca}^{+2}$ - cálcio; $\mathrm{Mg}^{+2}$ - magnésio; $\mathrm{K}$ - potássio, CTC - capacidade de troca de cátions; H+Al - hidrogênio e alumínio; P - fósforo; M.0 - matéria orgânica; V - saturação de bases; C - carbono

Tabela 2- Genótipos do Banco Ativo de Germoplasma de Amendoim Forrageiro da Embrapa Acre utilizados na determinação da densidade de esporos e identificação das espécies de fungos micorrízicos arbusculares presentes em sua rizosfera

\begin{tabular}{|c|c|c|}
\hline Identificação & BRA & Espécie \\
\hline 1 & 014931 & A. pintoi \\
\hline 2 & 037036 & A. pintoi \\
\hline 3 & 033260 & A. repens \\
\hline 4 & 039985 & A. pintoi \\
\hline 5 & 039799 & A. pintoi \\
\hline 6 & 035068 & A. pintoi $\times$ A. repens \\
\hline 7 & 035017 & A. pintoi $\times$ A. pintoi \\
\hline 8 & 035041 & A. pintoi $\times$ A. pintoi \\
\hline 9 & 035009 & A. pintoi $\times$ A. pintoi \\
\hline 10 & 035033 & A. pintoi $\times$ A. pintoi \\
\hline 11 & 040894 & A. pintoi \\
\hline 12 & 030333 & A. pintoi \\
\hline 13 & 029220 & A. repens \\
\hline 14 & 039187 & A. pintoi \\
\hline 15 & 014991 & A. pintoi \\
\hline 16 & 015083 & A. pintoi \\
\hline 17 & 035114 & A. pintoi \\
\hline 18 & 032352 & A. repens \\
\hline 19 & 034436 & A. repens \\
\hline 20 & 032379 & A. repens \\
\hline 21 & 032344 & A. pintoi \\
\hline 22 & 032409 & A. pintoi \\
\hline 23 & 012122 & A. pintoi \\
\hline
\end{tabular}

de profundidade em diferentes áreas do Banco Ativo de Germoplasma, com o objetivo de determinar a densidade de esporos de FMAs em locais com ausência da leguminosa forrageira e ocupado por vegetação espontânea dominada por gramíneas (principalmente Brachiaria plantaginea (Link) Hitchc.) e algumas folhas largas (principalmente Phyllanthus tenellus Roxb.). As amostras de solo coletadas foram levadas para o Laboratório de Micorrizas da Embrapa Agrobiologia, em Seropédica, RJ, para determinação da densidade de esporos e identificação das espécies de FMAs.

A densidade de esporos do solo foi determinada por contagem em placa canelada, em microscópio estereoscópico (Stemi 2000-C, Zeiss, Göttingen, Alemanha), após os procedimentos de extração do solo por peneiramento úmido e centrifugação diferencial (Axio Scope A1, Zeiss, Göttingen, Alemanha), descritos por Gerdemann e Nicolson (1963) e por

\begin{tabular}{|c|c|c|}
\hline Identificação & BRA & Espécie \\
\hline 24 & ID 52* & A. pintoi \\
\hline 25 & 014982 & A. pintoi \\
\hline 26 & 030325 & A. pintoi \\
\hline 27 & 030601 & A. pintoi \\
\hline 28 & 030635 & A. pintoi \\
\hline 29 & 031275 & A. pintoi \\
\hline 30 & 031461 & A. pintoi \\
\hline 31 & 031828 & A. pintoi \\
\hline 32 & 034100 & A. pintoi \\
\hline 33 & 039772 & A. pintoi \\
\hline 34 & 040045 & A. pintoi \\
\hline 35 & 012106 & A. repens \\
\hline 36 & 029190 & A. repens \\
\hline 37 & 029203 & A. repens \\
\hline 38 & 035025 & A. pintoi $\times$ A. pintoi \\
\hline 39 & 039080 & A. pintoi $\times$ A. pintoi \\
\hline 40 & 039128 & A. pintoi $\times$ A. pintoi \\
\hline 41 & 035076 & A. pintoi $\times$ A. repens \\
\hline 42 & 038857 & A. pintoi $\times$ A. repens \\
\hline 43 & 030384 & A. pintoi \\
\hline 44 & 040550 & A. pintoi \\
\hline 45 & 032409 & A. pintoi \\
\hline
\end{tabular}

* Identificação loc

Jenkins (1964), usando peneiras de 0,48 e 0,053 mm, e uma alíquota de $50 \mathrm{~cm}^{3}$ de solo de cada amostra.

Posteriormente, com auxílio de uma pisseta os esporos foram transferidos para uma placa de Petri, onde foram homogeneizados por movimentos circulares e deixados precipitar ao fundo. Entáo os esporos precipitados no espaço de um quarto da placa de Petri foram separados, agrupados conforme tamanho, cor, forma e transferidos para uma lâmina para microscopia dividida em dois grupos. O primeiro grupo foi colocado na lâmina sob uma lamínula com o montante álcool polivinil em lactoglicerol (PVLG). O segundo grupo de esporos foi montado com PVLG + reagente de Melzer (1:1) sob outra lamínula e quebrados delicadamente para a exposição das paredes germinativas, cuja reação de cor ao reagente de Melzer foi utilizada para auxiliar na identificação das espécies. 
de profundidade em diferentes áreas do Banco Ativo de Germoplasma, com o objetivo de determinar a densidade de esporos de FMAs em locais com ausência da leguminosa forrageira e ocupado por vegetação espontânea dominada por gramíneas (principalmente Brachiaria plantaginea (Link) Hitchc.) e algumas folhas largas (principalmente Phyllanthus tenellus Roxb.). As amostras de solo coletadas foram levadas para o Laboratório de Micorrizas da Embrapa Agrobiologia, em Seropédica, RJ, para determinação da densidade de esporos e identificação das espécies de FMAs.

A densidade de esporos do solo foi determinada por contagem em placa canelada, em microscópio estereoscópico (Stemi 2000-C, Zeiss, Göttingen, Alemanha), após os procedimentos de extração do solo por peneiramento úmido e centrifugação diferencial (Axio Scope A1, Zeiss, Göttingen, Alemanha), descritos por Gerdemann e Nicolson (1963) e por Jenkins (1964), usando peneiras de 0,48 e 0,053 mm, e uma alíquota de $50 \mathrm{~cm}^{3}$ de solo de cada amostra.

Posteriormente, com auxílio de uma pisseta os esporos foram transferidos para uma placa de Petri, onde foram homogeneizados por movimentos circulares e deixados precipitar ao fundo. Entâo os esporos precipitados no espaço de um quarto da placa de Petri foram separados, agrupados conforme tamanho, cor, forma e transferidos para uma lâmina para microscopia dividida em dois grupos. O primeiro grupo foi colocado na lâmina sob uma lamínula com o montante álcool polivinil em lactoglicerol (PVLG). O segundo grupo de esporos foi montado com PVLG + reagente de Melzer (1:1) sob outra lamínula e quebrados delicadamente para a exposição das paredes germinativas, cuja reação de cor ao reagente de Melzer foi utilizada para auxiliar na identificação das espécies.

A identificação das espécies de FMAs foi realizada observando as lâminas em microsópio óptico (Megafuge 1.0, Heraeus Separatech, Osterode am Harz, Alemanha Oriental) segundo Schenck e Pérez (1988) e comparando com as descriçóes originais das espécies e as descriçôes morfológicas disponíveis na página da International Culture Collection of Arbuscular Mycorrhizal Fungi - INVAM (http://invam.caf. wvu.edu). Os esporos foram identificados de acordo com a análise morfológica clássica descrito por Morton et al. (1995). Os caracteres taxonômicos incluíram número e tipo de camadas das paredes dos esporos e sua reação ao reagente de Melzer, características das paredes germinativas, quando presentes, morfologia da hifa de sustentaçáo no ponto de fixaçáo do esporo e variaçáo da cor e tamanho dos esporos. Foram usadas as seguintes medidas de diversidade para descrever as comunidades de fungos encontrados:

- Densidade de Esporos (contagem do número de esporos em $50 \mathrm{~cm} 3$ de solo);
- Riqueza de Espécies (contagem do número de espécies de FMAs identificadas em cada genótipo);

- Ocorrência relativa (OR) e Frequência Relativa (FR), em que:

$$
\begin{aligned}
& \text { OR }=\frac{n^{\circ} \text { de genótipos em que a espécie ocorre }}{n^{\circ} \text { de genótipos total }} \times 100 \\
& F R=\frac{n^{\circ} \text { de amostras em que a espécie ocorre }}{n^{\circ} \text { de amostras total }} \times 100
\end{aligned}
$$

Os dados de densidade de esporos foram submetidos à análise de variância, conforme delineamento inteiramente casualizado e as médias foram comparadas pelo teste de ScottKnott $1 \%$. As variáveis riquezas de espécies, ocorrência relativa e frequência relativa foram submetidas à análise descritiva, por serem avaliaçôes que resultam em apenas um valor para as três repetições amostrais. As análises estatísticas foram realizadas utilizando-se o programa computacional Genes (Cruz 2006).

\section{RESULTADOS}

Das 135 amostras de solo rizosférico de amendoim forrageiro, foram computados 91.604 esporos de FMAs, sendo verificada a ocorrência de 21 espécies para os 45 genótipos estudados. A análise de variância mostrou que a densidade de esporos variou significativamente $(p<0,01)$ entre os genótipos de amendoim forrageiro, indicando existir variabilidade genética para promoção da esporulação dos FMAs.

A densidade de esporos na rizosfera dos quarenta e cinco genótipos de amendoim forrageiro e das amostras testemunhas tomada em vegetaçáo espontânea dentro do Banco Ativo de Germoplasma é apresentada na Figura 1. Verifica-se que o teste de Scott-Knott ao nível de 1\% de probabilidade separou os 45 genótipos em quatro grupos distintos, sendo designados grupos 'a', 'b', 'c' e 'd', de acordo com as letras que receberam na aplicação deste teste estatístico.

Os genótipos do grupo 'à induziram uma alta esporulação dos FMAs, superior aos demais genótipos, com médias variando entre 1048 a 1289 esporos em $50 \mathrm{~mL}$ de solo. Neste grupo o genótipo 21 apresentou a maior variabilidade apresentando a amostra com densidade mínima e máxima, contendo respectivamente 640 e 1593 esporos em $50 \mathrm{~mL}$ de solo. Este grupo foi formado por sete genótipos, sendo cinco da espécie $A$. pintoi e dois híbridos interespecíficos de $A$. pintoi $\mathrm{x} A$. repens.

Os genótipos do grupo 'b' também promoveram maior esporulação dos FMAs comparado a vegetaçáo espontânea que ocorre na área do Banco Ativo de Germoplasma (amostras testemunhas, A1, A2 e A3). As médias deste grupo variaram 


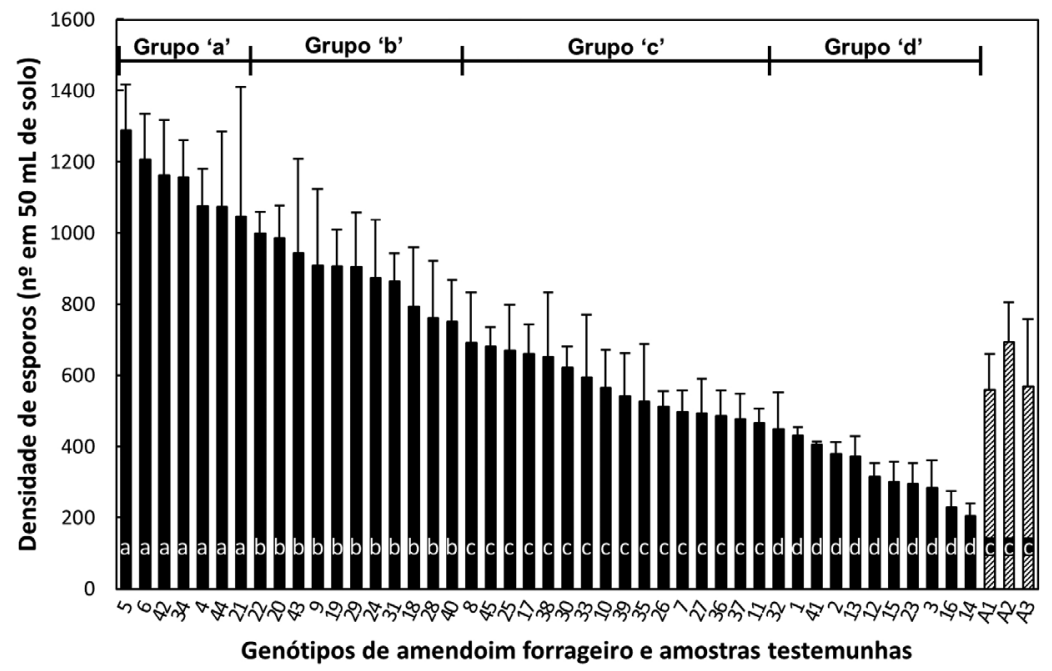

Figura 1- Densidade de esporos de Fungos Micorrízicos Arbusculares em amostras de solos rizosféricos de quarenta e cinco genótipos de amendoim forrageiro (barras pretas) e três amostras testemunhas em vegetação espontânea (barras hachuradas) dentro da área do Banco Ativo de Germoplasma da Embrapa Acre. A identificação dos 45 genótipos e seus códigos BRA encontra-se na Tabela 2. Barras com mesma letra não diferem entre si pelo teste de Scott-Knott a 1\% de probabilidade. Os grupos de genótipos foram divididos baseados na separação do teste de Scott-Knott 1\%, recebendo a denominação das letras que receberam no referido teste. Linhas acima das barras indicam o desvio padrão das médias. Coeficiente de variação da análise de variância $=25,7 \%$.

entre 752 a 999 esporos em $50 \mathrm{~mL}$ de solo. Este grupo foi formado por onze genótipos, sendo seis da espécie $A$. pintoi, três da espécie $A$. repens e dois híbridos intraespecíficos de $A$. pintoi $\mathrm{x} A$. pintoi.

Os genótipos do grupo 'c' promoveram esporulação dos FMAs similares a vegetação espontânea da área do Banco Ativo de Germoplasma. As médias deste grupo variaram entre 467 a 693 esporos em $50 \mathrm{~mL}$ de solo. Este grupo foi formado por dezesseis genótipos, sendo oito da espécie $A$. pintoi, três da espécie $A$. repens e cinco híbridos intraespecíficos de $A$. pintoi $\mathrm{x} A$. pintoi.

Os genótipos do grupo 'd' reduziram a esporulação dos FMAs comparado com a vegetaçáo espontânea da área do Banco Ativo de Germoplasma. As médias deste grupo variaram entre 152 a 361 esporos em $50 \mathrm{~mL}$ de solo. Este grupo foi formado por onze genótipos, sendo oito da espécie $A$. pintoi, dois da espécie $A$. repens e um híbrido interespecífico de $A$. pintoi $\mathrm{x} A$. repens.

As 21 espécies de FMAs identificadas nos 45 genótipos de amendoim forrageiro são apresentadas na Tabela 3. Elas pertencem a nove gêneros, sendo oito espécies de Acaulospora, três de Glomus, três de Scutellospora, duas de Racocetra, e uma espécie de cada um dos seguintes gêneros: Ambispora, Claroideoglomus, Funneliformis, Gigaspora, e Rhizophagus.

A ocorrência relativa das 21 espécies de FMAs nos 45 genótipos de amendoim forrageiro pode ser observada também na Tabela 3. Três espécies de FMAs apresentaram elevada ocorrência relativa, sendo elas Glomus macrocarpum,
Acaulospora tuberculata e Racocetra verrucosa, apresentado frequência relativa $100 \%, 97,8 \%$ e $88,9 \%$, respectivamente entre os 45 genótipos de amendoim forrageiro.

Outras espécies de FMAs foram raras, observando-se esporos em apenas um dos genótipos. Acaulospora colombiana foi recuperada apenas genótipo BRA 012122 (23) e Glomus tortuosum apenas no genótipo BRA 030325 (26) ambos de A. pintoi. Da mesma forma, Acaulospora laevis ocorreu apenas no genótipo BRA 034436 (19) de A. repens. A espécie Glomus ambisporum foi identificada apenas no genótipo BRA 035025 (38) e Scutellospora scutata apenas no genótipo BRA 039128 (40), ambos os genótipos sendo híbridos intraespecíficos de A. pintoi.

Outras espécies de FMAs também mostraram pouca ocorrência sendo recuperadas em apenas dois genótipos. A espécie Acaulospora rehmii foi extraída no genótipo BRA 033260 (3) de A. repens e no genótipo BRA 014991 (15) de A. pintoi. A espécie Acaulospora sporocarpia do genótipo BRA 035041 (8) de um híbrido intraespecífico de $A$. pintoi e do genótipo BRA 032352 (18) de A. repens. A espécie Rhizophagus fasciculatus foi identificada nos genótipos BRA 032344 (21) e BRA 039772 (33) ambos de A. pintoi, e Scutellospora pellucida nos genótipos BRA 037036 (2) e BRA 014991 (15), também ambos de $A$. pintoi.

A frequência relativa das 21 espécies de FMAs no total de amostras tomadas nos genótipos de amendoim forrageiro é apresentada na. As espécies Glomus macrocarpum, Acaulospora tuberculata e Racocetra verrucosa apresentam frequência 


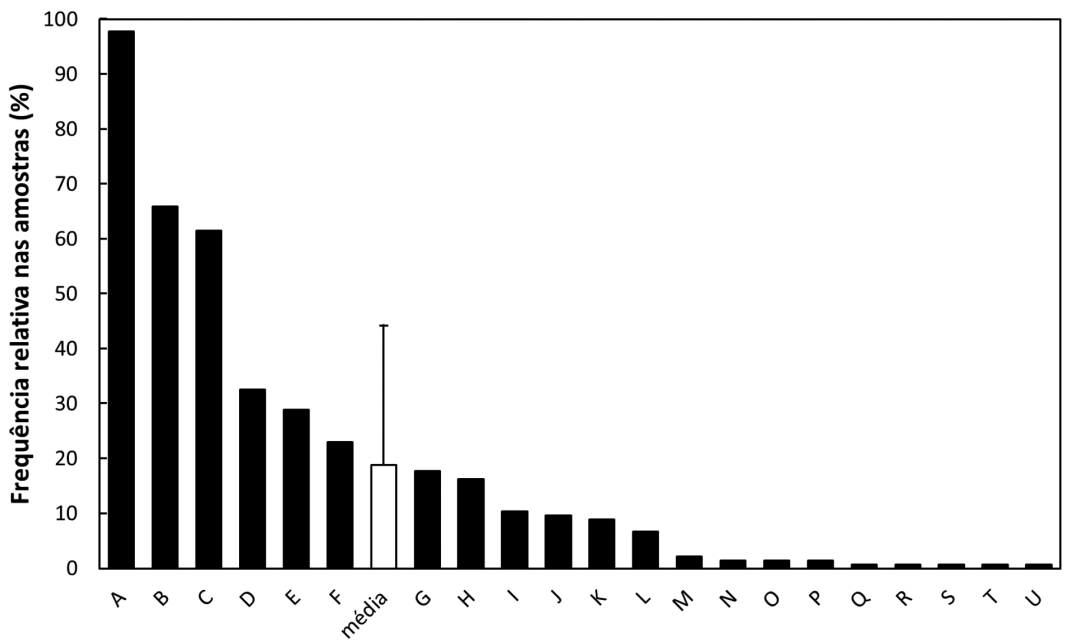

Espécie de Fungos Micorrízicos Arbusculares

Figura 2-Frequência relativa das 21 espécies de fungos micorrízicos arbusculares (barras pretas) levantadas nas amostras de solo rizosférico de 45 genótipos de amendoim forrageiro no Banco Ativo de Germoplasma da Embrapa Acre. A: Glomus macrocarpum; B: Acaulospora tuberculata; C: Racocetra verrucosa; D: Acaulospora mellea; E: Acaulospora scrobiculata; F: Scutellospora heterogama; G: Racocetra fulgida; H: Acaulospora foveata; I: Funneliformis verruculosus, J: Gigaspora sp; K: Ambispora leptoticha; L: Claroideoglomus lamellosum; M: Acaulospora rehmii; N: Acaulospora sporocarpia; 0: Rhizophagus fasciculatus; P: Scutellospora pellucida; Q: Acaulospora colombiana; R: Acaulospora laevis; S: Glomus ambisporum; T: Glomus tortuosum; U: Scutellospora scutata. Barra branca representa a média das frequências relativas e a linha sobre a barra indica o desvio padrão.

Tabela 3- Espécies de fungos micorrízicos arbusculares identificadas pelos esporos presentes na rizosfera de quarenta e cinco genótipos do Banco Ativo de Germoplasma de Amendoim Forrageiro da Embrapa Acre

\begin{tabular}{|c|c|c|c|}
\hline Família de Glomeromycota & Espécie identificada* & Genótipos em que a espécie foi observada** & $\begin{array}{c}\text { Ocorrência } \\
\text { relativa*** }(\%)\end{array}$ \\
\hline Acaulosporaceae & $\begin{array}{c}\text { Acaulospora colombiana (Spain \& N.C. Schenck) } \\
\text { Kaonongbua, J.B. Morton \& Bever }\end{array}$ & (23) & 2,2 \\
\hline Acaulosporaceae & Acaulospora foveata Trappe \& Janos & $\begin{array}{c}(8,12,13,14,18,20,24,25,29,31,33,36,38 \\
39,42,43,44,45)\end{array}$ & 40,0 \\
\hline Acaulosporaceae & Acaulospora laevis Gerd. \& Trappe & (19) & 2,2 \\
\hline Acaulosporaceae & Acaulospora mellea Spain \& N.C. Schenck & $\begin{array}{c}(2,3,4,5,6,9,10,11,12,14,15,16,17,18 \\
19,21,22,24,26,27,28,29,30,32,35,40,42 \\
43,44)\end{array}$ & 64,4 \\
\hline Acaulosporaceae & Acaulospora rehmii Sieverd. \& S. Toro & $(3,15)$ & 4,4 \\
\hline Acaulosporaceae & Acaulospora scrobiculata Trappe & $\begin{array}{c}(3,4,5,6,7,8,9,10,11,12,13,14,15,22,23 \\
26,28,32,35,36,37,42,43,44,45)\end{array}$ & 55,6 \\
\hline Acaulosporaceae & Acaulospora sporocarpia S.M. Berch & $(8,18)$ & 4,4 \\
\hline Acaulosporaceae & Acaulospora tuberculata Janos \& Trappe & (Ocorreu em 44 genótipos com exceção do genótipo 18) & 97,8 \\
\hline Ambisporaceae & $\begin{array}{c}\text { Ambispora leptoticha (N.C. Schenck \& G.S. Sm.) C. } \\
\text { Walker, Vestberg \& Schuessler }\end{array}$ & $(2,4,5,7,11,14,18,26,31,37,38)$ & 24,4 \\
\hline Claroideoglomeraceae & $\begin{array}{c}\text { Claroideoglomus lamellosum (Dalpé, Koske \& } \\
\text { Tews) C. Walker \& Schuessler }\end{array}$ & $(10,16,19,21,30,32,33,34,42)$ & 20,0 \\
\hline Gigasporaceae & Gigaspora sp & $(2,3,11,15,19,23,24,32,37,38,42)$ & 24,4 \\
\hline Gigasporaceae & $\begin{array}{l}\text { Racocetra fulgida (Koske \& C. Walker) Oehl, F.A. } \\
\text { Souza \& Sieverd. }\end{array}$ & $\begin{array}{c}(1,2,3,4,6,7,11,13,14,16,19,21,24,27,28 \\
29,31,34,42,43,45)\end{array}$ & 46,7 \\
\hline Gigasporaceae & $\begin{array}{l}\text { Racocetra verrucosa (Koske \& C. Walker) Oehl, F.A. } \\
\text { Souza \& Sieverd. }\end{array}$ & $\begin{array}{c}(1,2,3,5,6,7,8,9,11,12,13,14,16,17,18,19 \\
20,21,22,23,24,25,26,27,29,30,31,32,33 \\
34,35,36,37,38,39,41,42,43,44,45)\end{array}$ & 88,9 \\
\hline Gigasporaceae & $\begin{array}{c}\text { Scutellospora heterogama (T.H. Nicolson \& Gerd.) } \\
\text { C. Walker \& F.E. Sanders }\end{array}$ & $\begin{array}{c}(1,3,4,5,6,8,14,15,19,21,23,26,33,34,38 \\
40,42,43,44,45)\end{array}$ & 44,4 \\
\hline Gigasporaceae & $\begin{array}{l}\text { Scutellospora pellucida (T.H. Nicolson \& N. C. } \\
\text { Schenck) C. Walker \& F.E. Sanders }\end{array}$ & $(2,15)$ & 4,4 \\
\hline Gigasporaceae & Scutellospora scutata C. Walker \& Dieder. & $(40)$ & 2,2 \\
\hline
\end{tabular}


Tabela 3- Espécies de fungos micorrízicos arbusculares identificadas pelos esporos presentes na rizosfera de quarenta e cinco genótipos do Banco Ativo de Germoplasma de Amendoim Forrageiro da Embrapa Acre

\begin{tabular}{lccc}
\hline Família de Glomeromycota & Espécie identificada* & Genótipos em que a espécie foi observada** & $\begin{array}{c}\text { Ocorrência } \\
\text { relativa*** }(\%)\end{array}$ \\
\hline Glomeraceae & Funneliformis verruculosus & $(1,4,16,18,27,29,31,32,34,39,40,45)$ & 26,7 \\
Glomeraceae & (Błaszk.) C. Walker \& Schuessler & $(38)$ & 2,2 \\
Glomeraceae & Glomus ambisporum G.S. Sm. \& N.C. Schenck & (Ocorreu nos 45 genótipos de Arachis) & 100,0 \\
Glomeraceae & Glomus macrocarpum Tul. \& C. Tul. & $(26)$ & 2,2 \\
Glomeraceae & Glomus tortuosum N.C. Schenck \& G.S. Sm. & $(21,33)$ & 4,4 \\
\hline
\end{tabular}

*Nomenclatura das espécies conforme o site http://schuessler.userweb.mwn.de/amphylo/ consultado em 08/03/2013.

** a identificação dos 45 genótipos e seus BRA encontram-se na Tabela 2

*** Ocorrência relativa: $n^{0}$ de genótipos que a espécie ocorreu em relação ao total de genótipos

destacada das demais ocorrendo em $97,8 \%, 65,9 \%$ e $61,5 \%$ das 135 amostras tomadas nos 45 genótipos de amendoim forrageiro. Com uma frequência relativa próxima a média, variando de $32,6 \%$ a $6,7 \%$ das amostras foram verificadas as espécies Acaulospora mellea, Acaulospora scrobiculata, Scutellospora heterogama, Racocetra fulgida, Acaulospora foveata, Funneliformis verruculosus, Gigaspora sp, Ambispora leptoticha e Claroideoglomus lamellosum. As demais espécies de FMAs apresentaram frequência relativa variando entre $0,7 \%$ a 2,2\% das amostras.

A riqueza de espécies encontradas nos genótipos é apresentada na Figura 3. O genótipo BRA 38857 (42) apresentou a maior riqueza de espécies, sendo identificadas 10 espécies de FMAs na sua rizosfera. Já o genótipo BRA 35076 (41) apresentou a menor riqueza, com apenas três espécies recuperadas. Tanto o genótipo com riqueza máxima (42) como o com riqueza mínima (41) são híbridos interespecíficos de A. pintoi $\mathrm{x}$ A. repens.

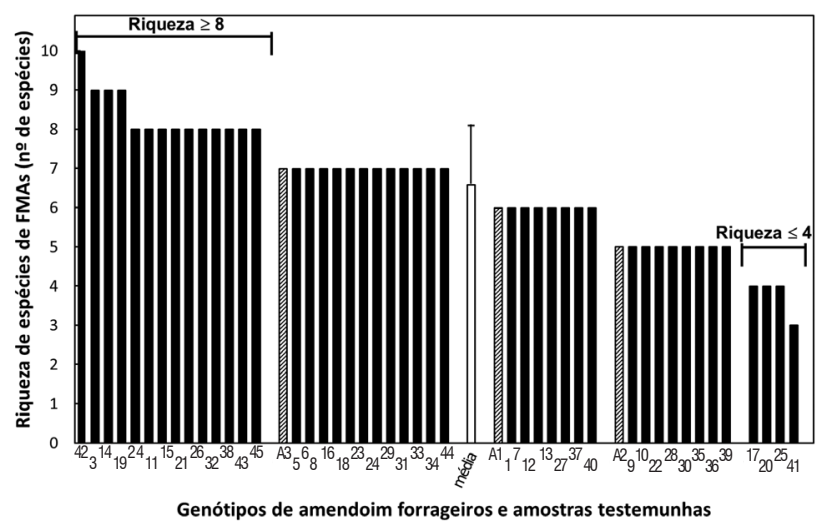

Figura 3- Riqueza de espécies de fungos micorrízicos arbusculares em quarenta e cinco genótipos de amendoim forrageiro (barras pretas) e três amostras testemunhas em vegetação espontânea (barras hachuradas) dentro da área do Banco Ativo de Germoplasma da Embrapa Acre. A identificação dos 45 genótipos e seus códigos BRA encontra-se na Tabela 2. Barra branca representa a média das riquezas de espécies dos genótipos e testemunhas e a linha sobre a barra indica o desvio padrão.
Na sequência dos genótipos com maior riqueza de espécies, estão os genótipos em que foram recuperadas nove espécies de FMAs, sendo eles BRA 39187 (14) de A. pintoi, BRA 33260 (3) eBRA 34436 (19) ambos de $A$. repens. Na grande maioria dos genótipos foram levantadas entre cinco e oito espécies de FMAs (Figura 3), sendo 10 genótipos com oito espécies, 12 genótipos com sete espécies, sete genótipos com seis espécies e oito genótipos com cinco espécies. Somente três genótipos apresentaram uma riqueza de quatro espécies de FMAs, sendo o BRA 32379 (20) de A. repens, o BRA 35114 (17) e o BRA 14982 (25), ambos de $A$. pintoi.

As amostras testemunhas (A1, A2 e A3) coletadas na ausência do amendoim, em área ocupada por vegetação espontânea, mostrou uma riqueza de espécies intermediária (A1 - 5 espécies de FMAs; A2 - seis espécies de FMAs; A3 sete espécies de FMAs), quando comparada à riqueza obtida nos diferentes genótipos.

Não houve relação entre a densidade de esporos e a riqueza de espécies dos genótipos. Os genótipos com menor (BRA 39187; 14) e maior (BRA 39799; 5) densidade de esporos foram diferentes dos genótipos com menor (BRA 35076, 41) e maior (BRA 38857, 42) riqueza de FMAs. Esta falta de relaçấo foi confirmada pelo cálculo da correlação de Pearson que mostrou coeficiente de correlaçấo muito baixo $(r=0,079)$ e não significativo $(\mathrm{P}>0,05)$. $\mathrm{O}$ genótipo de $A$. pintoi $\mathrm{BRA}$ 39187 (14) que apresentou menor densidade de esporos foi um dos que apresentaram maior riqueza de espécies.

\section{DISCUSSÃO}

A recuperação de 21 espécies de FMAs e de grande quantidade de esporos em amostras tomadas de 45 genótipos de amendoim forrageiro plantados no Banco Ativo de Germoplasma da Embrapa Acre, cuja área é relativamente pequena e sob um mesmo tipo de solo, mostra a capacidade do amendoim forrageiro de manter a diversidade de FMAs e sugere que a variabilidade genética dos genótipos tenha auxiliado a manter alta a esporulação e a riqueza de espécies de 
FMAs. Quanto maior a diversidade vegetal, maior poderá ser a esporulação (Burrows e Pfleger, 2002) e consequentemente a diversidade de FMAs estimada pela identificação morfológica destes esporos. O Banco Ativo de Germoplasma apresentou número de espécies de FMAs comparável aos agrossistemas mais complexos estudados por Miranda et al. (2010), confirmando que esta leguminosa pode aumentar a quantidade de FMAs e ampliar a diversidade de sua comunidade no solo.

Os resultados obtidos com o levantamento de espécies de FMAs no Banco Ativo de Germoplasma são relevantes, pois existem poucos estudos sobre a ocorrência de FMAs nos agroecossistemas amazônicos (Stürmer e Siqueira 2008; Souza et al. 2010). O presente estudo junto com o de Miranda et al. (2010), que também fazem levantamento das espécies de FMAs em pastagens com amendoim forrageiro na estação experimental da Embrapa Acre, e o estudo de Alfaro Villatoro (2004), que levanta os FMAs em um sistema agroflorestal de café com cobertura de $A$. pintoi na Guatemala, foram os poucos conseguidos durante a busca de bibliografia. Estes estudos concordam em várias espécies de FMAs ocorrentes em amendoim forrageiro, sendo as espécies Acaulospora foveata, Acaulospora mellea, Acaulospora scrobiculata e Glomus macrocarpum observadas nos três levantamentos. Miranda et al. (2010) observam também as espécies Acaulospora colombiana, Acaulospora laevis, Acaulospora tuberculata, Glomus tortuosum, Scutellospora heterogama e Scutellospora scutata, corroborando o presente estudo. Náo foram encontrados outros estudos de FMAs com $A$. repens, sendo provavelmente este o primeiro levantamento de FMAs nesta espécie de planta.

Os genótipos de amendoim forrageiro, de forma geral, proporcionaram alta densidade de esporos quando comparados a outras plantas estudadas por Durazzini et al. (2009) e Ramos et al. (2012). As amostras testemunhas (A1, A2 e A3) coletadas no Banco Ativo de Germoplasma em locais com vegetação espontânea mostram o quanto alguns genótipos de amendoim (pertencentes aos grupos 'a' e 'b') podem promover a esporulação mais que outras plantas (Figura 1). Como a densidade de esporos entre as amostras testemunhas foi similar, as variações de densidade de esporos nos genótipos de amendoim forrageiro se devem, provavelmente, as características genéticas que controlam a associação micorrízica, as quais são complexas e ainda pouco desvendadas (David-Schwartz et al. 2001; Kiriachek et al. 2009).

A grande capacidade do amendoim forrageiro de promover a esporulação de FMAs é evidente em vários estudos. Miranda et al. (2010) que estudou vários consórcios de $A$. pintoi em pastagens, com café e com a capoeira nativa, chegou a observar 1999 esporos por $50 \mathrm{~mL}$ de solo no consórcio A. pintoi x Brachiaria brizantha $\mathrm{x}$ Pueraria phaseoloides na estação seca, $\mathrm{e}$ 1275 esporos por $50 \mathrm{~mL}$ de solo no monocultivo do genótipo
BRA 40550 (44) durante a estaçáo chuvosa, valor este que concorda com o obtido para este genótipo no presente estudo (Figura 1). Na formação de mudas em casa de vegetação, há relato de $A$. pintoi promover uma densidade de mais 15.000 esporos por $50 \mathrm{~mL}$ de solo com a espécie Rhizophagus clarus (Miranda et al. 2008).

Apesar desta grande capacidade de promover a esporulação de FMAs, no presente estudo verificou-se que existem vários genótipos que promovem esporulação similar a da vegetação espontânea do Banco Ativo de Germoplasma (genótipos do grupo 'c'; Figura 1). Estes aparentemente não apresentam esse potencial promotor da esporulação de FMAs. Existem também genótipos de amendoim forrageiro com baixa capacidade de promover a esporulação de FMAs (genótipos do grupo 'd'). Estes promovem uma esporulação menor do que a vegetação espontânea da área do Banco Ativo de Germoplasma.

A densidade de esporos não é uma variável que indique diretamente o benefício que a planta obtém da simbiose (Weber et al. 2004). Outros estudos devem ser realizados avaliando os genótipos quanto ao benefício que obtém dos FMAs sobre o crescimento e acúmulo de nutriente. Genótipos de mamoeiro (Carica papaya L.) demonstram potencial genético diferenciado para a resposta a inoculação de FMAs (Trindade et al. 2001). O mesmo ocorre com genótipos de acerola (Malpighia emarginata DC.) (Costa et al. 2001). Weber et al. 2004 verificaram que Claroideoglomus etunicatus e Scutellospora sp apresentaram a maior e menor esporulação, respectivamente, mas contribuíram igualmente para o incremento da biomassa do cajueiro anão precoce (Anacardium occidentale L.). Todavia, o número de esporos de FMAs no solo não deixa de ser um indicativo da interação benéfica e funcional estabelecida entre a leguminosa e o fungo (Benedetti et al. 2005).

Os genótipos de $A$. repens não participaram do grupo 'a' cujos genótipos promoveram as maiores densidades de esporos de FMAs. Esta espécie apresentou genótipos distribuídos nos grupos 'b', 'c' e 'd'. Já os genótipos pertencentes a espécie $A$. pintoi foram alocados nos quatro grupos formados pelo teste de Scott-Knott, mostrando grande variabilidade na promoçáo de esporulaçáo dos FMAs. Os híbridos intraespecíficos de $A$. pintoi x $A$. pintoi apresentaram-se distribuídos nos grupos 'b' e 'c', mostrando menor variabilidade que os genótipos não híbridos desta espécie. Já os híbridos interespecíficos de A. pintoi $\mathrm{x}$ A. repens foram distribuídos nos grupos 'a' e 'd', sugerindo grande variabilidade na promoçáo da esporulação. $\mathrm{O}$ híbrido interespecífico de $A$. pintoi x $A$. repens $\mathrm{BRA}$ 035068 que ficou alocado no grupo 'a' tem o seu progenitor A. repens (BRA 29220) alocado no grupo 'd'. Considerando o pequeno número de híbridos interespecíficos avaliados neste estudo, não é possível fazer inferências significativas, porém houve tendência de os híbridos interespecíficos ampliarem a 
promoção de esporulaçáo em relação ao parental $A$. repens, enquanto que os híbridos intraespecíficos parecem ter diminuído a variabilidade na promoção da esporulação dos parentais A. pintoi.

Os genótipos de amendoim forrageiro estudados também apresentaram variabilidade para a riqueza de espécies de FMAs (Figura 3). O genótipo BRA 38857 (42) que apresentou a maior riqueza de espécies e o genótipo BRA 35076 (41) que apresentou a menor riqueza são ambos híbridos interespecíficos de $A$. pinto $i$ x $A$. repens, evidenciando mais diferenças entre estes dois genótipos híbridos, além da promoção da esporulação. A maioria dos genótipos (específicos e híbridos) apresentou uma riqueza intermediária com cinco a oito espécies de FMAs levantadas, comparável às amostras testemunhas de vegetação espontânea que apresentaram riqueza entre cinco e sete espécies. Os genótipos com riqueza elevada (nove espécies de FMAs) e com riqueza reduzida (quatro espécies de FMAs) foram divididos entre as espécies $A$. repens e $A$. pintoi, não evidenciando uma tendência clara de divisão destas espécies quanto a promoção da diversidade de FMAs.

A falta de relaçáo entre a densidade de esporos e a riqueza de espécies nos genótipos, confirmada pelo baixíssimo coeficiente de correlação de Pearson $(\mathrm{r}=0,079$; $\mathrm{P}>0,05)$, pode ter sido influenciado pelo esforço amostral, pois devido ao grande número de esporos nas amostras, apenas um quarto deles foi montado em lâminas para a sua identificaçấo taxônomica. Entretanto, não é provável que isso tenha influenciado significativamente este resultado, pois o princípio da amostragem foi respeitado (Cochran 1977). Em campo e em culturas armadilhas de FMAs é comum que na presença de espécies com esporulação muito agressiva, outras espécies sejam inibidas por competiçáo (Bartz et al. 2008; Leal et al. 2009), sendo essa a explicação mais plausível para o resultado verificado. Isso pode ser corroborado pelo genótipo de $A$. pintoi BRA 39187 (14), o qual apresentou a menor densidade de esporos e foi um dos que apresentaram maior riqueza de espécies.

Conforme ocorreu para densidade de esporos, a riqueza de espécies entre os genótipos variou em relação às amostras testemunhas na ausência de amendoim forrageiro. Tal resultado sugere que alguns genótipos de amendoim podem incrementar a riqueza de espécie de FMAs e outros diminuírem o número de espécies de FMAs identificadas por esporos.

O grande número de espécies de FMAs (21 espécies) encontradas nas áreas ocupadas por genótipos de amendoim forrageiro em monocultivo foi comparável ao esperado em ecossistemas nativos e diversos ainda não cultivados (MoreiraSouza et al. 2003), pois em sistemas agrícolas esse número pode sofrer uma redução dependendo do manejo e cultura. Segundo Douds e Millner (1999), o tipo de prática agrícola e as plantas cultivadas podem influenciar na riqueza de espécies de FMAs, com número podendo variar de 3 a 34 espécies. Além disso, fatores como monocultivo, manejo e fertilidade do solo exercem significativa influência na ocorrência de espécies e quantidade de esporos de fungos micorrízicos (Silva et al. 2006). Conforme observado no presente estudo e também no de Miranda et al. (2010), o amendoim forrageiro em monocultivo, mesmo sendo um agrossistema de menor complexidade, favorece a ocorrência de diferentes espécies de FMAs. Isto sugere que esta leguminosa forrageira é pouco seletiva quanto a espécies de FMAs e se caracteriza como uma boa hospedeira para multiplicação dos FMAs. Isto pode estar associado à possibilidade do amendoim forrageiro produzir uma grande variabilidade de metabólicos secundários, como flavonóides, os quais comprovadamente estimulam o crescimento de FMAs (Romero e Siqueira 1996).

Três espécies de FMAs apresentaram elevada ocorrência relativa e frequência relativa (Tabela 3 ; ). Verifica-se que o G. macrocarpum destacou-se das demais espécies de FMAs, estando presente em $100 \%$ dos genótipos em $97,8 \%$ das amostras. Resultado similar foi obtido por Miranda et al. (2010), que verificou a presença de Glomus macrocarpum em mais de $70 \%$ de suas amostras, sugerindo que este fungo pode ter alta afinidade com o amendoim forrageiro. Contudo, Glomus macrocarpum apresenta grande capacidade de adaptaçáo a diferentes solos submetidos a diferentes variaçôes nos teores de matéria orgânica, calagem, textura, entre outros fatores (Carrenho et al. 2001b), demonstrando ser uma espécie altamente resistente e adaptada a solos brasileiros, sendo a mais frequente em vários levantamentos realizados no Brasil (Carrenho et al. 2001a; Bartz et al. 2008; Miranda et al. 2010). Já as espécies Acaulospora tuberculata e Racocetra verrucosa, que apresentaram ocorrência relativa de $97,8 \%$ e $88,9 \%$ dos genótipos e uma frequência relativa de $65,9 \%$ e $61,5 \%$ das amostras, respectivamente, não são tão comuns nos levantamentos realizados no Brasil. Desta forma, a alta frequência verificada no presente estudo pode realmente estar associada à afinidade e adaptação destas espécies ao amendoim forrageiro e ao solo do Banco Ativo de Germoplasma da Embrapa Acre. Estas espécies mais frequentes na maioria dos genótipos e amostras merecem ser estudadas quanto à eficiência de promoção de crescimento e nutriçấo de genótipos de Arachis.

As espécies Acaulospora colombiana, Acaulospora laevis, Glomus ambisporum, Glomus tortuosum e Scutellospora scutata apresentaram ocorrência relativa de $2,2 \%$ dos genótipos (ocorreram em apenas um genótipo) e frequência relativa de $0,7 \%$ das amostras. Desta forma, isto sugere que são espécies raras ou pouco esporulantes (Husband et al. 2002) ou ainda apresentam muita baixa afinidade e adaptação ao amendoim forrageiro e ao solo do Banco Ativo de Germoplasma. Como as 
espécies A. colombiana e A. laevis possuem frequência elevada em outros levantamentos feitos no Brasil (Caproni et al. 2003; Carrenho et al. 2001b), sugere que estas espécies realmente tiveram baixa adaptação aos genótipos e ao solo.

\section{CONCLUSÕES}

Existe variabilidade genética entre os genótipos de amendoim forrageiro quanto à promoção da esporulação de fungos micorrízicos arbusculares (FMAs) e quanto à riqueza de espécies de FMAs nas suas rizosferas, característica esta que pode ser utilizada na seleçâo de plantas. Dos genótipos de amendoim forrageiro, quarenta por cento deles (pertencentes aos grupos 'a' e 'b') apresentaram a capacidade de estimular a esporulação de FMAs, ampliando a comunidade destes fungos em relação à vegetaçấo espontânea. Não houve comportamento claramente definido que diferenciasse as espécies $A$. pintoi, A. repens e seus híbridos inter e intraespecíficos quanto à promoção de esporulação e riqueza de espécies de FMAs. As espécies de FMAs Glomus macrocarpum, Acaulospora tuberculata, Racocetra verrucosa possuem alta presença na rizosfera dos genótipos de amendoim forrageiro, devendo ser estudadas visando sua introduçáo na cultura.

\section{AGRADECIMENTOS}

Ao $\mathrm{CNPq}$ - pelo apoio finaceirro.

A Embrapa Acre e Embrapa Agrobiologia - pela colaboração na realização deste trabalho.

\section{BIBLIOGRAFIA CITADA}

Alfaro Villatoro, M.A. 2004. Matéria orgânica e indicadores biológicos da qualidade do solo na cultrura do café sob manejo agroflorestal e orgânico. Tese de Doutorado, Universidade Federal Rural do Rio de Janeiro, Seropédica, Rio de Janeiro. 186p.

Andrade, C.M.S. de; Garcia, R.; Valentim, J.F.; Pereira, O.G. 2006. Grazing management strategies for massaigrass-forage peanut pastures: 1. Dynamics of sward condition and botanical composition. Revista Brasileira de Zootecnia, 35: 334-342.

Bartz, M.L.C.; Carrenho, R.; Gomes-da-Costa, S.M.; Colozzi Filho, A.; Tormena, C.A. 2008. Comparação entre as técnicas de amostragem direta em campo e cultura-armadilha para mensuração da diversidade de espécies de fungos micorrízicos arbusculares. Hoehnea, 35: 159-164.

Benedetti, T.; Antoniolli, Z.I.; Giracca, E.M.N.; Steffen, R.B. 2005. Diversidade de fungos micorrízicos arbusculares na cultura do milho após uso de espécies de plantas de cobertura de solo. Revista de Ciências Agroveterinárias, 4: 44-51.

Burrows, R.L.; Pfleger, F.L. 2002. Arbuscular mycorrhizal fungi respond to increasing plant diversity. Canadian Journal of Botany, 80: 120-130.

Caproni, A.L.; Franco, A.A.; Berbara, R.L.L. 2003. Capacidade infectiva de fungos micorrizicos arbusculares em áreas reflorestadas após mineração de bauxita no Pará. Pesquisa Agropecuária Brasileira, 38: 937-945.

Carrenho , R.; Trufem, S.F.B.; Bononi, V.L.R. 2001a. Fungos micorrízicos arbusculares em rizosferas de três espécies de fitobiontes instaladas em área de mata ciliar revegetada. Acta Botanica Brasilica, 15: 115-124.

Carrenho, R.; Silva, E.S.; Trufem, S.F.B.; Bononi, V.L.R. 2001b. Successive cultivation of maize and agricultural practices on root colonization, number of spores and species of arbuscular mycorrhizal fungi. Brazilian Journal of Microbiology, 32: 262270.

Cochran, W. G. 1977. Sampling Techniques, Third Edition, John Wiley \& Sons, New York, 1977, 428p.

Costa, C.M.C.; Maia, L.C.; Cavalcante, U.M.T.; Nogueira, R.J.M.C. 2001. Influência de fungos micorrízicos arbusculares sobre o crescimento de dois genótipos de aceroleira (Malpighia emarginata D.C.). Pesquisa Agropecuária Brasileira, 36: 893901.

Cruz, C.D. 2006. Programa Genes: Análise multivariada e simulação. Ed. UFV, Viçosa (MG), 2006, 175p.

David-Schwartz, R.; Badani, H.; Smadar, W.; Levy, A.A.; Galili, G.; Kapulnik, Y. 2001. Identification of a novel genetically controlled step in mycorrhizal colonization: plant resistance to infection by fungal spores but not extra-radical hyphae. The Plant Journal, 27: 561-569.

Douds, D.D.; Millner, P.D. 1999. Biodiversity of arbuscular mycorrhizal fungi in agroecosystems. Agriculture, Ecosystems and Environment, 74: 77-93.

Durazzini, A.M.S.; Pereira, J. de M.; Rocha, L.C.D.; Pereira, A.J. 2009. Fungos micorrízicos arbusculares em solos sob diferentes cultivos. Revista Agrogeoambiental, 1: 01-07.

Gerdemann, J.W.; Nicolson, T.H. 1963. Spores of mycorrhizal endogone species extracted from soil by wet sieving and decanting. Transactions British Mycological Society, 46: 235244.

Gómez-Carabalí, A.; Rao, I.M.; Otero, J.T. 2011. Influence of fertilization, season, and forage species in presence of arbuscular mycorrhizae in a degraded Andisoil of Colombia. Acta Agronomica, 60: 84-92.

Husband, R.; Herre, E.A.; Turner, S.L.; Gallery, R.; Young, J.P. 2002. Molecular diversity of arbuscular mycorrhizal fungi and patterns of host association over time and space in a tropical forest. Molecular Ecology, 11: 2669-2678.

Janos, D.P. 1988. Mycorrhiza applications in tropical forestry are temperate-zone approaches appropriate? In: $\mathrm{Ng}$, F.S.P. (Ed.). Trees and mycorrhiza. Forest Research Institute, Kuala Lumpur, 1988, 133-188p.

Janos, D.P. 2007. Plant responsiveness to mycorrhizas differs from dependence upon mycorrhizas. Mycorrhiza, 17: 75-91.

Jenkins, W.R.A. 1964. Rapid centrifugal-floration technique for separating nematodes from soil. Plant Disease Reporter, 48: 692.

Kiriachek, S.G.; Azevedo, L.C.B. de; Peres, L.E.P.; Lambais, M.R. 2009. Regulação do desenvolvimento de micorrizas arbusculares. Revista Brasileira de Ciência do Solo, 33: 1-16. 
Leal, P.L.; Stürmer; S.L.; Siqueira, J.O. 2009. Occurrence and diversity of arbuscular mycorrhizal fungi in trap cultures from soils under different land use systems in the Amazon, Brazil Brazilian Journal of Microbiology, 40: 111-121.

Miranda, E.M. de; Saggin Junior, O.J.; Silva, E.M.R. da. 2008. Seleção de fungos micorrízicos arbusculares para o amendoim forrageiro consorciado com braquiária. Pesquisa Agropecuária Brasileira, 43: 1185-1191.

Miranda, E.M. de; Silva, E.M.R. da; Saggin Junior, O.J. 2010. Comunidades de fungos micorrízicos arbusculares associados ao amendoim forrageiro em pastagens consorciadas no Estado do Acre, Brasil. Acta Amazonica, 40: 13-22.

Moreira-Souza, M.; Trufem, S.F.B.; Gomes-da-Costa, S.M.; Cardoso, E.J.B.N. 2003. Arbuscular mycorrhizal fungi associated with Araucaria angustifolia (Bert) O. Ktze Mycorrhiza, 13: 211-215.

Morton, J.B, Bentinvenga, S.P.; Bever, J.D. 1995. Discovery, measurement, and interpretation of diversity in symbiotic endomycorrhizal fungi (Glomales, Zygomycetes). Canadian Journal of Botany, 73 (suppl. 1): S25-S32.

Programa Estadual de Zoneamento Ecológico-Econômico do Acre. 2006. Zoneamento ecológico-econômico do Acre Fase II: documento síntese. Escala 1:250.000. il. Color. Secretaria de Estado de Planejamento e Desenvolvimento Econômico Sustentável, Rio Branco. 354 p.

Ramos, M.L.G.; Konrad, M.L.F.; Silva, D.E.; Ribeiro Junior, W.Q.; Batista, L.M.T. 2012. Diversidade de fungos micorrízicos e colonização radicular, em forrageiras solteiras e em consórcio com milho. Bioscience Journal, 28: 235-244.

Romero, A.G.F.; Siqueira J.O. 1996. Atividade de flavonóides sobre esporos do fungo micorrízico Gigaspora gigantea in vitro. Pesquisa Agropecuária Brasileira, 37: 517-522.

Santos, I.P.A. dos; Pinto, J.C.; Siqueira, J.O.; Morais, A.R. de; Santos, C.L. dos. 2001. Interação fósforo, micorriza e nitrogênio na produçâo e qualidade de Arachis pintoi cv. Amarillo. Pasturas Tropicales, 23: 43-45.

Schenck, N.C.; Pérez, Y. 1988. Manual of the identification of VA mycorrhizal fungi. 2 ed. INVAN. University of Florida, Gainesville, 241p.
Silva, C.F. da; Pereira, M.G.; Silva, E.M.R. da; Correia, M.E.F.; Saggin-Junior, O.J. 2006. Fungos micorrízicos arbusculares em áreas no entorno do Parque Estadual da Serra do Mar em Ubatuba (SP). Revista Caatinga, 19: 1-10.

Soares, P.G.; Resende, A.S. de; Urquiaga, S.; Campello, E.F.C.; Franco, A.A. 2006. Estabelecimento, produção de fitomassa, acúmulo de macronutrientes e estimativa da fixação biológica de nitrogênio em Arachis. Pasturas Tropicales, 28: 18-25.

Souza, F.A.; Stürmer, S.L.; Carrenho, R.; Trufem, S.F.B. 2010. Classificação e taxonomia de fungos micorrízicos arbusculares e sua diversidade e ocorrência no Brasil. In: Siqueira, J.O.; Souza, F.A. de, Cardoso, E.J.B.N.; Tsai, S.M. (Orgs.). Micorrizas: 30 anos de Pesquisa no Brasil. Editora UFLA, Lavras, p. 15-73

Stürmer, S.L.; Siqueira, J.O. 2008. Diversidade de Fungos Micorrízicos Arbusculares em Ecossistemas Brasileiros. In: Moreira, F.M.S.; Siqueira, J.O.; Brussaard, L. (Orgs.). Biodiversidade do Solo em Ecossistemas Brasileiros. Editora UFLA, Lavras, p. 537-583.

Trindade, A.V.; Dantas, J.L.L.; Almeida, F.P.; Maia, I.C. S. 2001. Estimativa do coeficiente de determinação genotípica em mamoeiros (Carica papaya L.) inoculados com fungo micorrízico arbuscular. Revista Brasileira de Fruticultura, 23: 607-612.

Van der Heijden, E.W.; Kuyper, T.W. 2001. Does origin of mycorrhizal fungus or mycorrhizal plant influence effectiveness of the mycorrhizal symbiosis? Plant and Soil, 230: 161-174.

Weber, O.B.; Souza, C.C.M. de; Gondin, D.M.F.; Oliveira, F.N.S.; Crisóstomo, L.A.; Caproni A.L.; Saggin Júnior, O.J. 2004. Inoculação de fungos micorrízicos arbusculares e adubação fosfatada em mudas de cajueiro-anão-precoce. Pesquisa Agropecuária Brasileira, 39: 477-483.

Yang, F.Y.; Li, G.Z.; Zhang, D.E.; Christie, P.; Li, X.L.; Gai, J.P. 2010. Geographical and plant genotype effects on the formation of arbuscular mycorrhiza in Avena sativa and Avena nuda at different soil depths. Biology and Fertility of Soils, 46: 435-443.

Recebido em 21/03/2013

Aceito em 05/07/2013 
